\title{
Relooking Antecedents to Consumer Dissatisfaction through the Virtual Cosmos
}

\author{
Gary H. D' $\operatorname{costa}^{1} \&$ K. R. Jayasimha ${ }^{1}$ \\ ${ }^{1}$ IIM Indore, Madhya Pradesh, India \\ Correspondence: Gary H. D'costa, IIM Indore, Madhya Pradesh, 453556, India. Tel: 91-98-6736-4299. E-mail: \\ f14garyd@iimidr.ac.in or garyhermendcosta@gmail.com
}

Received: December 27, 2014 Accepted: January 15, 2015 Online Published: January 26, 2015

doi:10.5539/ijms.v7n1p117 URL: http://dx.doi.org/10.5539/ijms.v7n1p117

\begin{abstract}
The purpose of this paper is to identify antecedents contributing to consumer dissatisfaction in a virtual setting. The purpose is not to contravene existing work but rather extend the existing work on consumer dissatisfaction to virtual setting. While much of the literature till date focuses on consumer satisfaction in online buying, there are only a handful of papers describing consumer satisfaction in virtual purchases. This paper attempts to identify the antecedents contributing to consumer dissatisfaction in a virtual setting as an update to the existing antecedents on consumer dissatisfaction. While some of the antecedents are common in a virtual setting and real world, other antecedents may not be such as intangibility of the product purchase. The paper concludes with a discussion associated with launching new brands through virtual platforms and its impact on consumer dissatisfaction.
\end{abstract}

Keywords: consumer dissatisfaction, virtual buying, consumer covetousness, virtual world

\section{Introduction}

The popularity of virtual worlds is increasing and the number of users subscribing to this new type of social media is on the rise. In fact, the popularity of these virtual worlds like Second life is outnumbering that of traditional social media websites such as Facebook and MySpace (Note 1). Subscribers to such platforms usually don't pay a fee for registering themselves, however they pay for purchasing in-world virtual items such as clothing, footwear and furniture. There is immense interest amongst marketers to collect subscriber's purchase data for predicting real world purchases (Note 2).

These virtual worlds offer branded goods and services such as Dell computers, IBM and TAM Airlines that subscriber's spend on using virtual world currency (Note 3). Usually many virtual world sites host their own virtual currency exchanges wherein real world money is exchanged for virtual currency. The virtual currency can then be used for purchase of virtual items. For instance, in the popular game Need for Speed World users exchange real world money for Boost (virtual currency of the game) for purchase of new cars from manufacturers or cars from other users and other accessories. Similarly, in the game Second Life subscribers convert real world money to linden dollars at the linden exchange for purchase of virtual items for their avatars.

When subscribers purchase virtual goods and services in the virtual macrocosm they create a status image for their avatars in the virtual setting (Belk, 2013). Marketers are seeing an opportunity to tap consumers as there is growing usage to try out clothing, home paint colors, furniture with their avatar character; that is a "virtual try and buy" scenario which may then translate into a real world buying of that particular brand of a product or service. Hence consumer satisfaction in the virtual setting is gaining prominence as there is a change in the way consumers shop for their products and services. Surprisingly, the first place where people become aware of brands in the digital age is through the social media especially virtual worlds; hence marketers are closely monitoring the number of users subscribing to these services online (Guo \& Barnes, 2011).

Considering the complexity and dynamic environment under which a virtual world operates, it's truly a conundrum for marketers in trying and capturing perceived brand image. Also, virtual worlds are becoming the new medium for advertisements and for carrying out market tests for a new product (Varajão \& Morgado, 2011). One of the major issues that have been identified in virtual world buying is that there is no facility for return of these virtual goods if the purchaser is unhappy with the purchase. For instance, in the popular Habbo hotel game, 
once a subscriber buys furniture for the room there is no option to return it even if the subscriber is unhappy with the purchase decision. Even though there are several drawbacks to purchasing virtual goods, there are many subscribers actively involved in purchasing of these "coded goods" in exchange for virtual currency which is real money (Mennecke et al., 2008).

The motivation for the current work is the fact that the number of subscribers subscribing to social media sites especially virtual worlds called 3-D social media has significantly increased. Second life's Q4 results showed that the number of users have grown by $61 \%$ from 2007-08 (Note 4). It is observed that besides online purchasing through e-retailers for purchase of real world goods there was a steady rise in the purchase of virtual goods (Shelton, 2010). Therefore, there is a need for contrasting and comparing relative overlaps and differences in consumer satisfaction and dissatisfaction associated with purchase of goods in the real world and virtual world. Extant review of literature reveals that there is a significant discord in the way we look at consumer dissatisfaction in the real world which relies on product performance as one of the major causal antecedents in semblance to consumer dissatisfaction in the virtual world which is largely independent of product performance.

\section{Literature Review}

The reviewed literature placed emphasis on consumer satisfaction in product and service (real world) setting. Some of the earlier works by LaTour and Peat (1979) attempted to conceptualize post-consumption satisfaction through Thibaut and Kelly's (1959) "comparison level theory". According to this theory, consumer satisfaction with product performance is determined by the discrepancy between the outcome and an identified standard of comparison. Thus, outcomes above the comparison level reflect satisfaction while outcomes below the comparison level reflect dissatisfaction (LaTour \& Peat, 1979). One of the major identifiable drawbacks in this theory is that it does not account for satisfaction forming before the consumption experience.

Thus, in order to overcome this drawback the expectancy-disconfirmation framework was proposed in order to overcome the limitations of the "comparison level theory" (Churchill \& Surprenant, 1982). The current literature focuses extensively on the expectancy-disconfirmation framework for explaining consumer satisfaction and dissatisfaction which states that if product expectation meets performance then there is conformance otherwise there is disconfirmation (Churchill \& Surprenant, 1982). An empirical study carried out with regard to performance of apparel products in a university setting showed that performance expectation was a significant determinant of consumer satisfaction or dissatisfaction (Chen-Yu, Williams, \& Kincade, 1999).

While several researchers (Yuksel \& Yuksel, 2001; Halstead et al., 1994) have pointed out the limitations of the expectancy-disconfirmation framework in generating satisfaction formation; a more robust model was designed incorporating effects of attribute satisfaction and information satisfaction as predictive variables contributing to satisfaction formation (Spreng, MacKenzie, \& Olshavsky, 1996). Again, it is argued that this model relied more extensively on expectancy-disconfirmation paradigm (Churchill \& Surprenant, 1982) which attributes product performance to be a significant contributor in forming consumer satisfaction.

The social cognition model (Sirgy, 1984) provides an alternative explanation to consumer satisfaction which was designed to mathematically describe how discrepancies between and among cognitive constructs such as ideal, expected, deserved and perceived outcomes before and after purchase and usage of the product affect the consumer's level of satisfaction with the product (Sirgy, 1984). The social cognition model views consumer satisfaction/dissatisfaction as an emotional state rather than a motivational state.

The value-percept disparity theory also considers consumer satisfaction to be an emotional response however, a response generated by cognitive-evaluation processes. In this theory, the perceptions of an object are compared with a consumer's value, needs, wants or desires (Westbrook \& Reilly, 1983). According to this theory, "Greater the disparity between perceptions of the product and value, the greater is the dissatisfaction" (Yi, 1989). This theory only considers consumers immediate desires and needs and does not consider comparison of product performance with a specified standard of evaluation (Westbrook \& Reilly, 1983).

Extending the argument that consumer satisfaction/dissatisfaction is an emotional state rather than a motivational state; researchers argued that there is a need to distinguish between the types of emotions experienced by consumers and that not all negative emotions result in consumer dissatisfaction and this finding has been supported by focus group and lab experiments which has supported the model on "Dual role of emotions in consumer satisfaction/dissatisfaction" (Krishnan \& Olshavsky, 1995).

An attempt to explain consumer satisfaction formation was done through "Attribution theory" which considers attributions as interventions that exert influence on consumers after they have experienced a product-related outcome and prior to their next product purchase decision (Folkes, 1984; Weiner, 1992). An alternate hypothesis 
considers desire-congruency to be more appropriate in explaining consumer satisfaction/dissatisfaction over expectancy-disconfirmation framework (Wirtz \& Mattila, 2001).

This paper argues that there is a need to delineate consumer satisfaction and dissatisfaction in virtual purchases as buying in virtual setting is different from a real world setting such as product return in real world which is not available in the virtual world. Second, the impact of the purchased product tangibility in the real world gives satisfaction to a consumer as there is a "material exchange" which is only one-sided in a virtual setting. This alternative viewpoint on consumer dissatisfaction in a virtual macrocosm is of great value to marketers as this is the first place in the digital age that subscribers first encounter a brand. This paper can help companies develop a better marketing strategy on whether to introduce a new brand at a "price" in the virtual setting and how consumer dissatisfaction can be minimized in virtual purchases.

\section{The Framework}

The framework is introduced in two stages. In the first stage, the buyer and user are defined in a virtual setting and in the second stage as indicated in Figure 1-(Antecedents and Consequences of Consumer Dissatisfaction in a Virtual Macrocosm) we describe a conceptual framework for the following discussion. In short, the framework comprises of three sets of factors: (1) antecedents that encourage or discourage consumer dissatisfaction in a virtual setting, (2) consumer dissatisfaction construct in a virtual setting, (3) consequences of consumer dissatisfaction in a virtual setting. We discuss each of these three factors in depth and develop propositions based on the literature.

\subsection{Buyer and User in a Virtual Setting}

There is a need to delineate the buyer and user in a virtual setting mainly because of the relational complexities existing between them. For instance, the buyer in a virtual setting is the subscriber which will further be referring to as the "physical being" and the user of the purchased product which will further be referred to as the "virtual being". Drawing from the work of Herbert Simon's (1987) "Bounded rationality" it is argued that the two beings cannot be in perfect unison with each other due to dynamic interdependencies existing between rationality conjoined with the physical being and emotions conjoined with the virtual being. Thus, the pre-consumption decision is governed by emotions whereas post-consumption evaluation is governed by rationality which evokes consumer dissatisfaction after the consumption event has occurred.

\subsection{Antecedents to Consumer Dissatisfaction in a Virtual Setting}

We argue that unmet consumer expectations are just one facet to consumer dissatisfaction in virtual consumption and that product performance is one front in consumer expectations in the virtual scenario. We identified several factors to consumer dissatisfaction from the literature with intent to study it in a virtual setting comprising mainly of unmet consumer expectations (cf. Churchill \& Surprenant, 1982), product intangibility (Shemwell et al., 1998) and ancillary technical difficulties as key antecedents enhancing or dampening consumer dissatisfaction in a virtual setting.

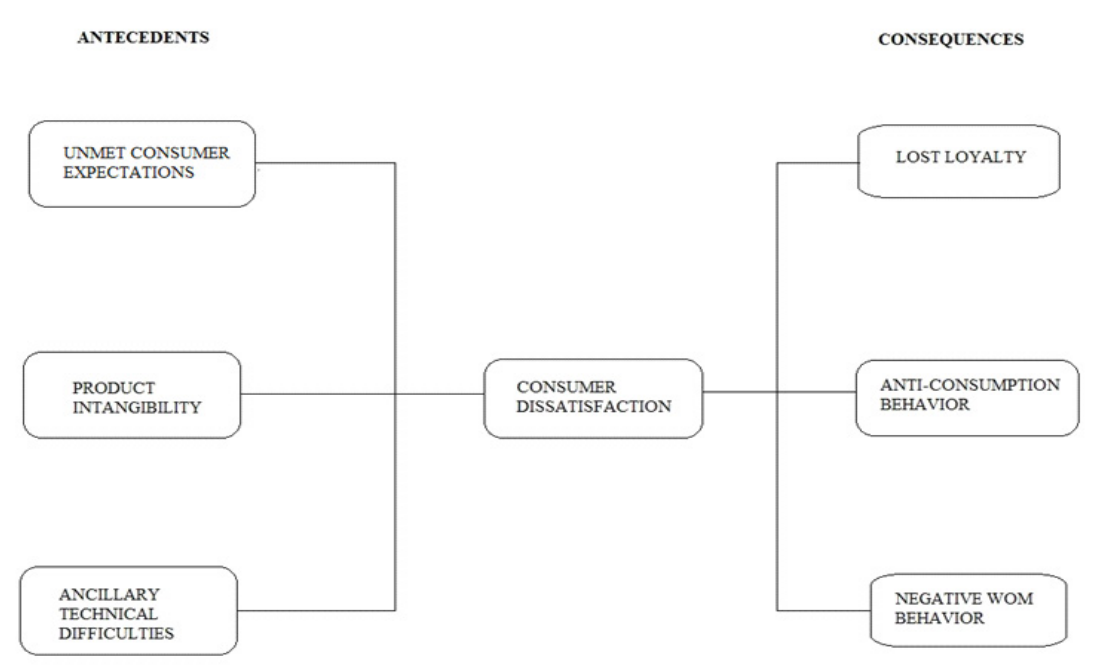

Figure 1. Antecedents and consequences of consumer dissatisfaction in a virtual macrocosm 


\subsubsection{Unmet Consumer Expectations}

We state several factors of unmet consumer expectations such as undefined product performance, product return policies (cf. Colburn, 2013) and consumer covetousness as indicated in Figure 2. For instance, the virtual product is of no significance to the physical being whereas it serves a "function" in the virtual world independent of product performance per se in the real world. In such a case since there is no visually observable product performance associated with the product purchase. We conjecture consumer dissatisfaction is likely to occur to the physical being post product purchase in the virtual setting. Thus:

P1: Greater the degree of undefined product performance, higher is the consumer dissatisfaction from virtual purchases.

Unlike product returns that are possible in the real world, return of virtual products in virtual buying is not possible. Thus, in such a case the product serves no function and may not be accepted well by peer groups that can generate consumer dissatisfaction in the physical being on account of improper mechanisms in place for return of virtual products purchased (Mennecke et al., 2008). For instance, in the game Need for Speed World there is no facility for return of virtual items purchased in the game and compensation in such cases is mainly done through virtual currency however this still accounts for consumer dissatisfaction as this in-game currency or Boost is not convertible to real world money on account of absence of a proper exchange. While on the contrary, in the game Second Life consumers cannot return virtual goods purchased from virtual store merchant's however compensation is done through the virtual currency "linden dollars" and the physical being has reduced consumer dissatisfaction in such a scenario on account of the virtual currency being able to be exchanged to real world currency through the virtual world's linden exchange. Hence:

P2: Greater the ease of return, lesser is the consumer dissatisfaction from virtual purchases.

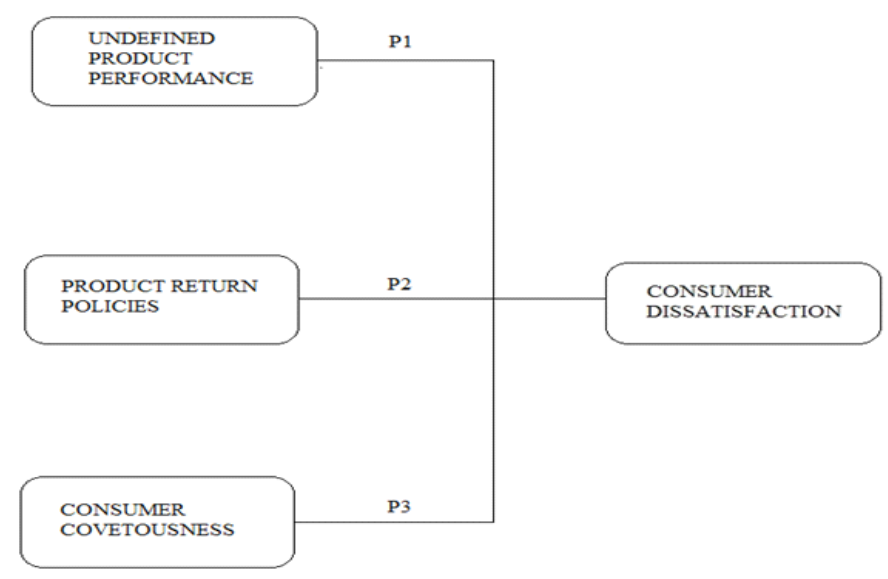

Figure 2. Unmet consumer expectations and consumer dissatisfaction

Consumer covetousness is one major antecedent to consumer dissatisfaction in virtual setting. In case of virtual purchases, the "intent to purchase" is driven based on what others possess; this is what is called consumer covetousness. While in the real world consumer covetousness is greatly tapped on by marketers in launching a marketing campaign; in the digital world consumer covetousness (Barkhi et al., 2008) is tapped on by peer groups which instigate purchases in virtual settings irrespective of a marketing campaign being adopted or not. For instance, Apple relies on consumer covetousness to facilitate repeat purchases through dissatisfaction arising from not having the latest product (Note 5). Thus:

P3: Greater the degree of consumer covetousness greater the dissatisfaction due to constant spending of virtual currency-"pain of paying" (Prelec \& Loewenstein, 1998).

\subsubsection{Product Intangibility}

Every consumer equates product benefit to cost of paying for the product-Customer Value proposition (Kordupleski, 2003). However, in a virtual setting, the virtual product offers no benefit to the physical being and this can be mainly attributed to intangibility associated with virtual product purchases. Consumers want to feel 
that they have got their money's worth but when consumers emotionally detach themselves from their virtual being rationality dominates and generates dissatisfaction through cognitive evaluation processes (Deci, 1975). However, if there is a small proportion of tangibility associated with the virtual product purchase experience such as "certificate of ownership" sent via mail, consumer dissatisfaction can be reduced or avoided in such instances. Hence:

P4: Greater the level of intangibility associated with the virtual product purchased, greater is the consumer dissatisfaction (Shemwell et al., 1998)

\subsubsection{Ancillary technical difficulties}

Ancillary technical difficulties can arise from both host-side and subscriber-side as indicated in Figure 3. While, these do not directly contribute to consumer satisfaction or dissatisfaction at time of purchase we cannot discount its significance in forming customer satisfaction or dissatisfaction post-purchase.

Host-side technical difficulties include problems in "coding". As all these virtual goods and services are nothing but computer codes, a "buggy code" designed by a programmer can result in improper "visual treatment" of the virtual object resulting in consumer dissatisfaction to the "physical being". Hence:

P5: Greater the host-side technical difficulties, greater is the level of consumer dissatisfaction.

In case of subscriber-side, the technical difficulties can be multifarious. In case the virtual world platform is incompatible with the subscriber's graphic card; then it can result in "improper visual treatment" of the virtual objects or there can be a "lag" in the virtual experience. Unfamiliarity with regard to the usage of the virtual possessions purchased can result in consumer dissatisfaction to the "physical being". Thus:

P6: Greater the subscriber-side technical difficulties, greater is the level of consumer dissatisfaction.

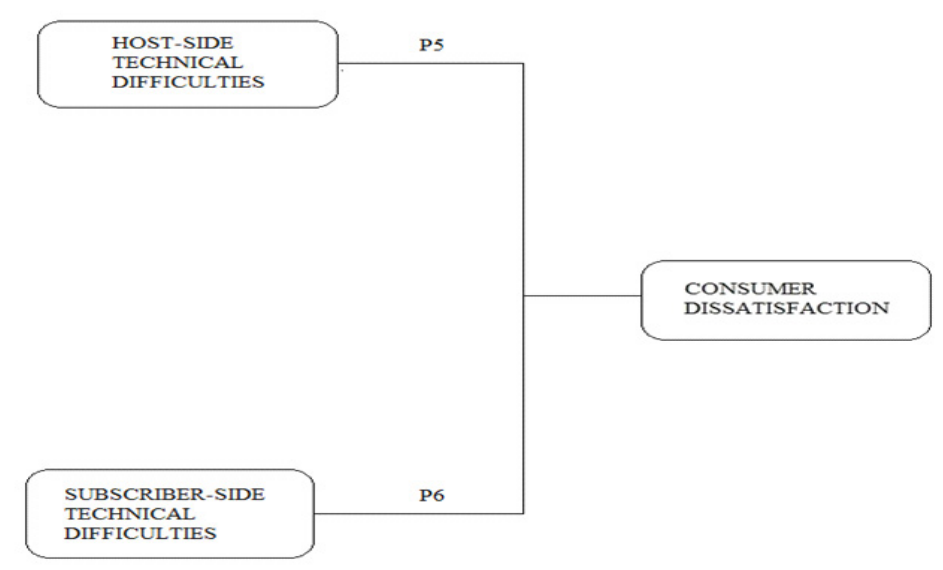

Figure 3. Ancillary technical difficulties and consumer dissatisfaction

\subsection{Consequences of Consumer Dissatisfaction in a Virtual Setting}

While the purpose of this paper was to dwell attention upon antecedents to consumer dissatisfaction and the need to look at consumer dissatisfaction well beyond the looking-glass of the expectancy-disconfirmation paradigm; we only fleeting touch upon some of the consequences that occur on account of consumer dissatisfaction in the virtual setting as there is considerable overlap in the consequences of consumer dissatisfaction in the virtual world with that of the real world.

Based upon the early work of Hirschman's (1970) response framework which has been recognized in various fields including psychology and consumer behavior (Singh, 1991). According to Hirschman's dissatisfaction response model, consumers will behave in one of the three ways in response to a dissatisfactory purchase experience. There may be a loss of loyalty, exit behavior or consumers may engage in voicing. It is important to note that such behavior involving loyalty, exit and voicing are not mutually exclusive responses (Singh, 1990). These responses can be utilized individually or together by a consumer who is dissatisfied. 
Consumer dissatisfaction in a virtual setting can prevent repeat purchase behaviors from merchants that results in lost loyalty (Fraering \& Minor, 2013). In a virtual setting it is very difficult to predict the degree to which a customer may be loyal to a particular brand or merchant. At this stage, a consumer may not quit completely from purchase of virtual goods; however repeated purchases from a particular merchant or brand may cease to take place. Thus:

P7: Greater the degree of consumer dissatisfaction, greater is the reduction in purchases (Fraering \& Minor, 2013)

When consumers choose to exit, they break all ties with the selling or servicing company. While this has clearly been documented in real world, we cannot negate its validity in the virtual world since there are many merchants selling virtual goods in a virtual universe that consumers can decide to exit if the dissatisfaction is severe. While exit does not imply not buying virtual goods; it does imply rather failure to purchase goods of a particular brand or from a particular merchant in a virtual setting. This can trigger anti-consumption behavior on account of dissatisfaction if the cause of dissatisfaction continues to persist due to common underlying antecedents described earlier that may not be neutralized by the new seller the consumer intends to buy from. Anti-consumption behavior is the ultimate consequence of consumer dissatisfaction wherein a consumer may be lost forever and regaining back the lost customer from this stage may be very difficult if not next to impossible (Lee, Motion, \& Conroy, 2009). Thus:

P8: Greater the level of consumer dissatisfaction, greater the tendency to indulge in anti-consumption behavior

Voicing is not considered to be a very strong consequence to consumer dissatisfaction since, due to absence of product performance, there may be no desire to change the situation from undesirable to desirable; in addition consumers also need to search for alternate seller's who are selling the same good they wish to purchase which may be difficult in a virtual setting due to patents and trademark regulations that prevent other merchants from reproducing designs and ideas of other merchants just like in the real world.

However what can be a more severe consequence of consumer dissatisfaction is negative word of mouth (WOM) behavior exhibited by consumers (Singh, 1990). In addition to consumers not taking out time to address the seller about the dissatisfaction experienced with the virtual good, most of the times in virtual setting consumers communicate to other users through chat windows available in the virtual world platforms but not the seller directly about the dissatisfaction experienced with regard to product purchase. Hence:

P9: Greater the level of consumer dissatisfaction, greater is the negative e-WOM behavior.

\section{Discussion}

The framework can be helpful to marketers in a variety of ways. For instance, stage 1 of the framework isolates buyer and user in a virtual setting that can help marketers in positioning products that are relatively new to consumers through effective virtual world advertisement mediums (Note 6). Also, marketers must understand that this is the place where consumers will first encounter the brand and therefore any negative experiences associated with the brand in the virtual world can translate over into the real world popularly referred to as the spillover effect in Marketing (Erdem \& Sun, 2002).

What marketers must keep in mind is that there is a dynamic engagement going on in the mind of the consumer between "rational buying" and "emotional buying" that can influence satisfaction outcome through compulsive and impulsive behaviors (Faber, 2010). It is important to note that the virtual world is a hybrid in between goods and services. The second stage of our framework comprises of antecedents that are exclusive to the virtual setting. While some of the antecedents can be linked to consumer dissatisfaction through the expectancy-disconfirmation framework (Churchill \& Surprenant, 1982) other antecedents are linked through more complex models proposed by various researchers who have contributed to explaining satisfaction formation through the various models described in the literature survey.

Not only is this helpful to marketers but also to academicians considering the fact that over many decades researchers have tried to explain consumer satisfaction in a holistic view only to encounter limitations with every model (Kim, Magnusen, \& Kim, 2014).Considering how the internet-age has evolved, the explanation to consumer satisfaction gets even more complex and by highlighting these new "digital antecedents" to consumer dissatisfaction in a virtual setting we wish to capture the entire picture of consumer satisfaction and dissatisfaction formation through the virtual lens. 


\section{Limitations}

One major limitation in the model proposed is that unlike the value-percept disparity model (Westbrook \& Reilly, 1983) the model assumes that dynamic conflict between rationality and emotions in virtual expectation formation generates satisfaction or dissatisfaction. As of now our propositions have not been tested empirically, therefore until we verify our propositions empirically we can only conjecture this framework to be at the conceptual level.

We have not stated any linkages among the components escalating to dissatisfaction formation as this would need empirical testing. Another key assumption made while explaining dissatisfaction formation is that there is uncoupling between the physical being and the virtual being which may not always be the case. One of the major limitations that prevent operational working of the framework happens to be the issue of the scales employed in measuring consumer satisfaction or dissatisfaction in the virtual setting as well as the real world (Hausknecht, 1990).

\section{Conclusion}

This paper makes its contribution to scholarship literature on several fronts. First, this was the first attempt made to point out antecedents to consumer dissatisfaction and satisfaction formation in a virtual setting. Second, it was the first time that the buyer and user were treated separately in lieu of consumer satisfaction and dissatisfaction in the virtual cosmos.

Pointing out the limitations of the expectancy disconfirmation paradigm (Churchill \& Surprenant, 1982) in explaining satisfaction formation in the virtual setting it is suggested that there is a need for a hybrid model encompassing the use of value-percept disparity theory (Westbrook \& Reilly, 1983) in explaining dissatisfaction formation in a virtual setting.

Thus, this paper can help managers gain a different insight into satisfaction associated with virtual purchases and can help them act in a proactive and decisive manner seeking a tradeoff between launching a new brand in the real world versus the virtual world considering what is at stake for the company with regard to its customers.

\section{References}

Barkhi, R., Belanger, F., \& Hicks, J. (2008). A Model of the Determinants of Purchasing from Virtual Stores. Journal of Organizational Computing and Electronic Commerce, 18(3), 177-196. http://dx.doi.org/10.1080/10919390802198840

Belk, R. (2013). Extended Self in a Digital World. Journal of Consumer Research, 40, 477-500. http://dx.doi.org/10.1086/671052

Chen-Yu, H., Williams, G., \& Kincade, D. (1999). Determinants of Consumer Satisfaction/Dissatisfaction with the Performance of Apparel Products. Family and Consumer Sciences Research Journal, 28(2), 167-192. http://dx.doi.org/10.1177/1077727X99282003

Churchill, G. A., \& Suprenant, C. (1982). An investigation into the determinants of customer satisfaction. Journal of Marketing Research, 19(4), 491-504

Colburn, R. T. (2013). Determining the Effect of the Returns Management Experience on Consumer Satisfaction. University of Tennessee Honors Thesis Projects.

Deci, E. L. (1975). Intrinsic motivation. New York: Plenum.

Erdem, T., \& Sun, B. (2002). An Empirical Investigation of the Spillover Effects of Advertising and Sales Promotions in Umbrella Branding. Journal of Marketing Research, 39(4), 408-420. http://dx.doi.org/10.1509/jmkr.39.4.408.19120

Faber, R. J. (2010). Impulsive and Compulsive Buying. Wiley International Encyclopedia of Marketing. http://dx.doi.org/10.1002/9781444316568.wiem03007

Folkes, V. S. (1984). Consumer reactions to product failure: an attributional approach. Journal of Consumer Research, 10(4), 398-409.

Fraering, M., \& Minor, M. S. (2013). Beyond loyalty: customer satisfaction, loyalty, and fortitude. Journal of Services Marketing, 27(4), 334-344.

Guo, Y., \& Barnes, S. (2011). Purchase behavior in virtual worlds: An empirical investigation in Second Life. Information \& Management, 48(7), 303-312. http://dx.doi.org/10.1016/j.im.2011.07.004 
Halstead, D., Hartman, D., \& Schmidt, L. S. (1994). Multi source Effects on the Satisfaction Formation Process. Journal of the Academy of Marketing Science, 22(2), 114-129. http://dx.doi.org/10.1177/0092070394222002

Hausknecht, D. (1990). Measurement Scales in Consumer Satisfaction/Dissatisfaction. $C S / D \& C B, 3,1-11$.

Hirschman, A. (1970). Exit, voice and loyalty: Responses to decline in firms, organizations and states. Cambridge, MA: Harvard University Press.

Kim, J., Magnusen, M., \& Kim, Y. (2014). A Critical Review of Theoretical and Methodological Issues in Consumer Satisfaction Research and Recommendations for Future Sport Marketing Scholarship. Journal of Sport Management, 28, 338-355. http://dx.doi.org/10.1123/jsm.2013-0084

Kordupleski, R. (2003). Mastering customer value management: The art and science of creating competitive advantage. Cincinnati, $\mathrm{OH}$ : Pinnaflex Educational Resource.

Krishnan, H., \& Olshavsky, R. (1995). The Dual Role of Emotions in Consumer Satisfaction/Dissatisfaction. Advances in Consumer Research, 22, 454-459.

LaTour, S. A., \& Peat, N. C. (1979). Conceptual and methodological issues in consumer satisfaction research. Advances in Consumer Research. Association for Consumer Research (U.S.), 6(1), 31-37.

Lee, M., Motion, J., \& Conroy, D. (2009). Anti-consumption and Brand Avoidance. Journal of Business Research, 62(2), 169-180. http://dx.doi.org/10.1016/j.jbusres.2008.01.024

Mennecke, B., McNeill, D., Roche, E., Bray, D., Townsend, A., \& Lester, J. (2008). Second Life and Other Virtual Worlds: A Roadmap for Research. Communications of the Association for Information Systems, 22(20), 371-388.

Prelec, D., \& Loewenstein, G. (1998). The Red and the Black: Mental Accounting of Savings and Debt. Marketing Science, 17(1), 4-28.

Shelton, A. (2010). Defining the lines between virtual and real world purchases: Second Life sells, but who's buying? Computers in Human Behavior, 26(6), 1223-1227. http://dx.doi.org/10.1016/j.chb.2010.03.019

Shemwell, D., Yavas, U., \& Bilgin, Z. (1998). Customer-service provider relationships: An empirical test of a model of service quality, satisfaction and relationship-oriented outcomes. International Journal of Service Industry Management, 9(2), 155-168. http://dx.doi.org/10.1108/09564239810210505

Simon, H. (1987). Making Management Decisions: The Role of Intuition and Emotion. Academy of Management Executive, 57-64.

Singh, J. (1990). Voice, exit, and negative word-of-mouth behaviors: An investigation across three service categories. Journal of the Academy of Marketing Science, 18(1), 1-15. http://dx.doi.org/10.1007/BF02729758

Singh, J. (1991). Industry characteristics and consumer dissatisfaction. Journal of Consumer Affairs, 25(1), 19-55. http://dx.doi.org/10.1111/j.1745-6606.1991.tb00279.x

Sirgy, M. (1984). A social cognition model of consumer satisfaction/dissatisfaction an experiment. Psychology and Marketing, 1(2), 27-44. http://dx.doi.org/10.1002/mar.4220010205

Spreng, R., Mackenzie, S., \& Olshavsky, R. (1996). A Reexamination of the Determinants of Consumer Satisfaction. Journal of Marketing, 60(3), 15-32.

Thibaut, J. W., \& Kelly, H. H. (1959). The social psychology of groups. New York: Wiley.

Varajão, J., \& Morgado, L. (2011). Potential of virtual worlds for marketing tests of product prototypes. Journal of the Textile Institute, 1(8), 1-8. http://dx.doi.org/10.1080/00405000.2011.639513

Weiner, B. (1992). Human motivation: Metaphors, theories, and research. Newbury Park, CA: Sage.

Westbrook, R. A., \& Reilly, M. D. (1983). Value-percept disparity: an alternative to the disconfirmation of expectations theory of consumer satisfaction. Advances in Consumer Research. Association for Consumer Research (U.S.), 10, 256-261.

Wirtz, J., \& Mattila, A. (2001). Exploring the Role of Alternative Perceived Performance Measures and NeedsCongruency in the Consumer Satisfaction Process. Journal of Consumer Psychology, 11(3), 181-192. http://dx.doi.org/10.1207/S15327663JCP1103_04 
Yi, Y. (1989). A critical review of consumer satisfaction. Retrieved October 26, 2014, from http://deepblue.lib.umich.edu/bitstream/2027.42/36290/1/b1412322.0001.001.pdf

Yuksel, A., \& Yuksel, F. (2001). The Expectancy-Disconfirmation Paradigm: A Critique. Journal of Hospitality \& Tourism Research, 25(2), 107-131. http://dx.doi.org/10.1177/109634800102500201

\section{Notes}

Note 1. Linden, Z. (2009, January 15). Second Life Residents logged nearly 400 million hours in 2008, growing 61\% over 2007. Retrieved October 26, 2014.

Note 2. Ahmad, M., Shen, C., Srivastava, J., \& Contractor, N. (2014). Predicting Real World Behaviors from Virtual World Data. Switzerland: Springer International Publishing.

Note 3. List of real companies and organisations in Second Life. (2009). Retrieved November 20, 2014, from http://www.nbhorizons.com/list.htm

Note 4. Adapted from Linden Lab's Annual report 2008。

Note 5. Moore, H. (2012, October 25). IWant: How Apple and the gadget-makers train consumers' covetousness. Retrieved October $\quad 26, \quad 2014, \quad$ from http://www.theguardian.com/commentisfree/2012/oct/25/iwant-apple-gadget-consumers

Note 6. Make Second Life a better place. (n.d.). Retrieved November 20, 2014, from http://www.secondads.com/

\section{Copyrights}

Copyright for this article is retained by the author(s), with first publication rights granted to the journal.

This is an open-access article distributed under the terms and conditions of the Creative Commons Attribution license (http://creativecommons.org/licenses/by/3.0/). 